\title{
Regulation of 2-Phosphoenolpyruvate Carboxykinase and Isocitrate Lyase Syntheses in Neurospora crassa
}

\author{
By R. E. BEEVER* \\ Department of Genetics, University of Leeds, Leeds LS2 $9 \mathrm{JT}$
}

(Received 23 September 1974)

INTRODUCTION

The regulation of the synthesis of isocitrate lyase, a key enzyme of the glyoxylate shunt pathway, has been widely studied in micro-organisms (Kornberg, I966; Flavell \& Woodward, 197I a). In contrast, little is known about the controls regulating synthesis of the metabolically related enzyme 2-phosphoenolpyruvate carboxykinase (PEP carboxykinase). In Neurospora crassa PEP carboxykinase, like isocitrate lyase, is present at very low levels during growth on sucrose but is derepressed during growth on acetate (Flavell \& Fincham, 1968). Conditions have been found, however, under which PEP carboxykinase and isocitrate lyase levels are not correlated. Consideration of these conditions leads to the hypothesis that PEP carboxykinase synthesis is regulated through repression by a glycolytic intermediate and that isocitrate lyase is regulated through repression by $\mathrm{C}_{4}$ acid common to the glyoxylate and tricarboxylic acid cycles.

\section{METHODS}

Strains. The wild-type strains ST $A$ and ST $a$ and the acetate-nonutilizing (acu-6) strain Ji 3 I of Neurospora crassa were as previously described (Beever \& Fincham, I973). The suc strain 393I I (FGSCI248) was obtained from the Fungal Genetics Stock Center, Humboldt State College, Arcata, U.S.A.

Media and culture conditions. The medium was Vogel's medium $\mathrm{N}$ supplemented with sucrose at $58 \mathrm{~mm}$ (sucrose medium) or acetate at $40 \mathrm{~mm}$ (acetate medium), as described by Beever \& Fincham (1973), except for Expt I (Table I) where all carbon sources were added at $40 \mathrm{~mm}$. Succinate was added as the sodium salt at $4.3 \mathrm{~mm}$. Crosses were made on the medium described by Westergaard \& Mitchell (1947).

Enzyme and protein assays. Assays for PEP carboxykinase (EC. 4. I I .a), isocitrate lyase (EC. 4.I.3.I), fumarate hydratase (EC. 4.2.I.2) and protein were as used previously (Beever \& Fincham, 1973). Enzyme units are expressed in $\mu \mathrm{mol}$ product formed $/ \mathrm{min}$.

\section{RESULTS}

Enzyme levels in wild-type and suc mutants on various carbon sources

Enzyme levels in wild-type and suc mutant mycelium growing on various carbon sources were measured (Table I). In addition to PEP carboxykinase and isocitrate lyase the tricarboxylic acid cycle enzyme, fumarate hydratase, was measured. Neurospora crassa 'suc' mutants lack the anaplerotic oxaloacetate-synthesizing enzyme, pyruvate carboxylase, and do not grow readily on sucrose alone but need a supplement of a tricarboxylic acid, such as succinate, or an allied metabolite (Strauss, 1957; Beever, 1973). On acetate these mutants

* Present address: Plant Diseases Division, D.S.I.R., Private Bag, Auckland, New Zealand. 
Table I. Enzyme level in wild-type ( $\mathrm{sT} A$ ) and mutant (suc) strains grown on various carbon sources

\begin{tabular}{|c|c|c|c|c|c|c|}
\hline \multirow[b]{2}{*}{ Carbon source } & \multirow[b]{2}{*}{ Strain } & \multirow[b]{2}{*}{$\begin{array}{l}\text { Period } \\
\text { of growth } \\
\text { (h) }\end{array}$} & \multirow[b]{2}{*}{$\begin{array}{l}\text { Fresh wt } \\
(\mathrm{g} / \mathrm{r} 00 \mathrm{ml})\end{array}$} & \multicolumn{3}{|c|}{ Specific activity* (units/mg protein) } \\
\hline & & & & $\begin{array}{c}\text { PEP } \\
\text { carboxykinase }\end{array}$ & $\begin{array}{l}\text { Isocitrate } \\
\text { lyase }\end{array}$ & $\begin{array}{l}\text { Fumarate } \\
\text { hydratase }\end{array}$ \\
\hline \multicolumn{7}{|c|}{ Expt. I } \\
\hline Acetate & ST $A$ & 22 & 0.28 & $0 \cdot 134$ & 0.247 & $I \cdot 662$ \\
\hline Sucrose & sT $A$ & 22 & $\mathrm{I} \cdot 04$ & 0.000 & 0.001 & 0.687 \\
\hline Sodium glutamate & ST $A$ & 124 & 0.04 & 0.060 & 0.015 & 0.586 \\
\hline Ethanol & ST $A$ & 46 & 0.04 & 0.135 & 0.065 & 0.658 \\
\hline Acetate + sucrose & ST $A$ & 22 & 0.48 & 0.016 & 0.007 & $I \cdot 352$ \\
\hline $\begin{array}{l}\text { Acetate + sodium } \\
\text { glutamate }\end{array}$ & st $A$ & 22 & $x^{0.35}$ & $0 \cdot 136$ & 0.184 & I 440 \\
\hline Sucrose & ST $A$ & 24 & 0.82 & 0.000 & 0.000 & 0.613 \\
\hline Sucrose & 393 I I & 120 & 0.96 & 0.005 & 0.027 & 0.197 \\
\hline Sucrose + succinate & ST $A$ & 24 & $0 \cdot 78$ & 0.001 & 0.000 & 0.607 \\
\hline Sucrose + succinate & 393 I I & 48 & 0.82 & 0.001 & 0.047 & 0.437 \\
\hline
\end{tabular}

* Activities are representative of at least two independent determinations.

grow as well as wild type and the specific activities of PEP carboxykinase, isocitrate lyase and fumarate hydratase are indistinguishable from those of wild type (unpublished observations). Under our liquid culture conditions the suc mutant 393 I s showed a lag of about $24 \mathrm{~h}$ before initiating rapid growth on sucrose medium plus succinate; in the absence of succinate the lag was about $96 \mathrm{~h}$. Wild type showed a lag of about six hours on both media.

\section{A gene which delays enzyme derepression after transfer to acetate}

Flavell (1967) observed that some acetate-nonutilizing mutants showed slow derepression of many acetate-utilizing enzymes following transfer from sucrose to acetate medium. In particular, one acu-6 strain, JI 3 I, showed almost no derepression of the following enzymes six hours after transfer to acetate medium: acetyl-CoA synthetase, isocitrate lyase, malate synthetase, PEP carboxykinase, citrate synthetase, fumarate hydratase, malate dehydrogenase. In other acu-6 strains derepression of all these enzymes, except PEP carboxykinase, occurred essentially as in wild type (Flavell \& Fincham, 1968) and the acu-6 locus is the structural gene for PEP carboxykinase (Beever \& Fincham, 1973). The anomalous derepression behaviour of strain JI 3I was confirmed by measuring levels of the enzymes isocitrate lyase and fumarate hydratase. It was found that some derepression of isocitrate lyase and fumarate hydratase did occur after $24 \mathrm{~h}$ incubation in acetate medium.

One hundred ascospores were isolated at random from a cross of strain JI 3 I to STa. Sixty spores germinated of which 23 were acetate-nonutilizers (acu-6). Derepression of isocitrate lyase was examined in I 5 progeny. Although some variation was observed between different isolates a pronounced reduction in ability to derepress this enzyme was found in 3 of the $6 a c u-6$ progeny and 3 of the $9 a c u-6^{+}$progeny. One $a c u-6^{+}$isolate (Ac-73-5, mating type $A$ ) with reduced ability to derepress isocitrate lyase, was chosen for more detailed study. Derepression curves for isocitrate lyase, PEP carboxykinase and fumarate hydratase were examined in isolates of an octad of ascospores dissected from the cross of strain Ac-73-5 to STa. Two parameters were chosen to characterize these curves: the lag before enzyme increase becomes linear, and the linear rate of enzyme increase. The spores could be grouped 
unequivocally into two classes with spore isolates I to 4 like wild type and spore isolates 5 to 8 mutant. Considering the isocitrate lyase data, and taking ST $A$ values as $100 \%$, the lag shown by isolates $\mathrm{I}$ to 4 ranged from $8 \mathrm{I}$ to $\mathrm{I} 3 \mathrm{I} \%$ and the linear rate of derepression from 82 to II $8 \%$. On the other hand isolates 5 to 8 showed a lag of 222 to $268 \%$ (Ac-73-5 showed $248 \%$ ) and a linear rate of enzyme derepression of 20 to $46 \%$ (Ac-73-5 showed $55 \%$ ). Strain AC-73-5 and isolates 5 to 8 also showed a low rate of derepression of PEP carboxykinase and fumarate hydratase. This is consistent with first division segregation of a single gene, spores $I$ to 4 being wild type and spores 5 to 8 mutant.

Strain Ac-73-5 could not be distinguished from wild type by growth rate on sucrose, acetate, glycerol or lactose when tested on solid media.

\section{DISCUSSION}

It is suggested that the synthesis of both PEP carboxykinase and isocitrate lyase is regulated by repression rather than induction. In mixtures with sucrose, acetate does not lead to high levels of the enzymes as would be predicted if acetate acted as inducer. There is no doubt that acetate enters the cell under these circumstances as growth is less than on the sugar alone and fumarate hydratase levels are present at derepressed levels. Further, Flavell \& Fincham (1968) showed that acetyl-CoA synthetase-deficient (acu-5) strains derepress both PEP carboxykinase and isocitrate lyase in wild-type fashion on transfer from sucrose to acetate medium. Similarly $a c u-3$ (isocitrate lyase deficient) strains derepress PEP carboxykinase in normal fashion. These observations argue against induction by metabolites that are derived from acetate.

The two groups of metabolites most likely to be involved in repression are intermediates of the glycolytic pathway, such as phosphoenolpyruvate, and the $\mathrm{C}_{4}$ acids common to the glyoxylate and tricarboxylic acid cycles, such as succinate, malate or oxaloacetate. In Neurospora crassa Flavell \& Woodward (I97I $a$ ) have argued that isocitrate lyase is regulated by the level of a glycolytic intermediate acting as repressor. The results presented here do not support this suggestion, especially when the variations in PEP carboxykinase levels are considered. The relatively sluggish response of suc mutants to succinate, and the fact that the mutants eventually grow without supplement, are consistent with the supply of $\mathrm{C}_{4}$ acids being growth-limiting during early growth of these mutants. The very low fumarate hydratase levels probably reflect this. Glycolytic intermediates are present at elevated levels during these early stages, and indeed, pyruvate accumulates in the medium (Strauss, 1957). The partial derepression of isocitrate lyase under these conditions argues against a glycolytic intermediate being its repressor but is consistent with a $\mathrm{C}_{4}$ tricarboxylic acid cycle intermediate acting as repressor. The repression of isocitrate lyase when glutamate is sole carbon source, and the partial repressing effect of glutamate when added to acetate, likewise support the proposal that $\mathrm{a}_{4}$ carboxylic acid is repressor. These arguments are reinforced when the behaviour of PEP carboxykinase, which links the $C_{4}$ acids with the $C_{3}$ glycolytic intermediates, is considered. The two conditions when levels of this enzyme are not correlated with those of isocitrate lyase are both consistent with the proposal that PEP carboxykinase is repressed by a glycolytic intermediate. During early growth of suc mutants, when glycolytic intermediates are probably elevated, PEP carboxykinase is repressed, and during growth on glutamate, when $\mathrm{C}_{3}$ intermediates are probably low, PEP carboxykinase is partially derepressed. It is suggested that all of these results support the hypothesis that PEP carboxykinase is repressed by high levels of a glycolytic intermediate and that isocitrate lyase is repressed by high levels of a $\mathrm{C}_{4}$ acid. 
The anomalous derepression in strains $\mathrm{JI} 3 \mathrm{I}$ and Ac-73-5 may reflect an alteration in the derepression system. The genetic analysis is consistent with the effect being, at least in large measure, due to a single gene difference at a locus unlinked to acu-6. In conjunction with the data of Flavell (1967), these results suggest that derepression of most of the enzymes normally derepressed on transfer to acetate is slowed in these strains. Attempts to overcome the lack of derepression by adding yeast extract, cyclic AMP, glutamate or succinate were unsuccessful (unpublished observations). A parallel may be drawn between the strains carrying this 'regulator' gene and the effect of inhibiting respiration at the time of transfer of wild type to acetate medium (Flavell \& Woodward, I97 I $b$ ).

I thank Dr R. B. Flavell for allowing me to quote unpublished data on strain J I 3 I and for his constructive criticism of the manuscript. The guidance of Professor J. R. S. Fincham is gratefully acknowledged. I am indebted to the New Zealand Meat Producers' Board for the award of a Sir Walter Mulholland Fellowship.

\section{REFERENCES}

BeEver, R. E. (1973). Pyruvate carboxylase and N. crassa 'suc' mutants. Neurospora Newsletter 20 , I5-16.

BeEver, R. E. \& Fincham, J. R. S. (I973). Acetate-nonutilizing mutants of Neurospora crassa: acu-6, the structural gene for PEP carboxykinase and inter-allelic complementation at the acu-6 locus. Molecular and General Genetics 126, 21 7-226.

Flavell, R. B. (1967). Genetic and biochemical studies on acetate metabolism in Neurospora crassa. Ph.D. thesis, University of East Anglia.

Flavell, R. B. \& Fincham, J. R. S. (1968). Acetate-nonutilizing mutants of Neurospora crassa. II. Biochemical deficiences and the roles of certain enzymes. Journal of Bacteriology 95, 1063-1068.

Flavell, R. B. \& Woodward, D. O. (197I $a$ ). Metabolic role, regulation of synthesis, cellular localization, and genetic control of the glyoxylate cycle enzymes in Neurospora crassa. Journal of Bacteriology I05, 200-210.

Flavell, R. B. \& WoodWard, D. O. (197I $b$ ). Selective inhibition of enzyme synthesis under conditions of respiratory inhibition. Journal of Bacteriology 107, 853-863.

KORNBERG, H. L. (1966). The role and control of the glyoxylate cycle in Escherichia coli. Biochemical Journal 99, I-I I.

Strauss, B. S. (1957). Oxalacetic carboxylase deficiency of the succinate-requiring mutants of Neurospora crassa. Journal of Biological Chemistry 225, 535-544.

WestergaARd, M. \& Mitchell, H. K. (1947). Neurospora V. A synthetic medium favouring sexual reproduction. American Journal of Botany 34, 573-577. 